\title{
Mobile, Modular and Adaptive Assembly Jigs for Large-Scale Products
}

\author{
Sebastian Hogreve, Katharina Krist and Kirsten Tracht 10
}

\begin{abstract}
The assembly of products is often supported by jigs. Especially for large dimensional products, jigs and fixtures are used to align the components and ensure the stability of the assembly until all parts are firmly mounted. This paper describes the development of mobile, modular and adaptive assembly jigs, which are designed to support ergonomic working in the production of high-lift systems for civil aircrafts. The jig supports the workers to adapt the position and orientation of the product to the current assembly operation. The fundamentals of the development are explained and the features of a concept, called assembly wheel, are presented. The assembly wheel consists of two or more robot arms on a circular seventh axis. The robot arms hold and position the components to be assembled so that all joining spots are freely accessible to the worker. The ergonomic benefits of the concept were examined in a study using a 3D model of the jig. A demonstrator on a scale of 1:2 was set up, with which real experiments with an adaptive jig can be conducted for evaluation.
\end{abstract}

\section{Keywords}

Assembly $\cdot$ Fixtures $\cdot$ Ergonomics $\cdot$ Aero-space industry

S. Hogreve $(\bowtie) \cdot$ K. Krist $\cdot$ K. Tracht

University of Bremen, Bremen Institute for Mechanical Engineering, Badgasteiner Str. 1, 28359

Bremen, Germany

e-mail: hogreve@bime.de

K. Krist

e-mail: krist@bime.de

T. Schüppstuhl et al. (eds.), Annals of Scientific Society for Assembly,

Handling and Industrial Robotics 2021,

https://doi.org/10.1007/978-3-030-74032-0_4 


\section{Introduction}

To assemble a product, individual parts are put together. By means of different joining operations, complex goods are created. The functionality and quality of an assembled product often depends on the precision of the alignment of the parts. This is the reason why during assembling a lot of effort is spend on measuring, positioning and adjusting of parts. For the production of serial products, it is common to support assembly processes through jigs. The jigs help to align the parts to be assembled and keep them in position until the joining process is completed. This reduces the desired number of handling tasks, fastens the production process and reduces the risk of assembly errors. Besides these advantages, jigs may also be necessary to ensure the initial fixation of the loose parts. An assembly group is sometimes fragile and limp until all parts are added and fixed. The jig supports the assembly group and prevents it from collapsing. Especially during the production of large-scale products, like aircraft components or railcar bodies, jigs are necessary to bring the parts in position and to support the mechanical structure.

Assembly fixtures are usually designed for a single process. Technical restrictions of the jig influence the assembly sequence, operations to be performed and force a certain posture of the assembler due to accessibility. Even though jigs and fixtures are usually designed to support an ergonomic working procedure, they are mostly inflexible and immovable. The device can only be adapted to changes in the production process or the product with great effort. Some fixtures do have adjustment options so that the worker can bring the product into an ergonomic position and orientation. However, these usually have only one degree of freedom and a limited range of movement. With large-scale assemblies, however, there is the challenge of having several technicians with different physiques and different needs working simultaneously on one assembly. In order to provide all assemblers with ergonomic access to the product at the same time, a much more complex jig design is required.

This paper presents the concept and the investigation results for a mobile, modular and adaptive assembly device. In this context adaptive needs to be understood as the capability to adapt to the assembly situation and the workers physical needs. The jig has been developed according to an example from the aerospace industry and it has been investigated using its 3D CAD model. Furthermore, for evaluation of ergonomics and process capability a reduced scale demonstrator of a mobile, modular and adaptive jig has been designed and built. The application product used for these investigations is a high-lift system of a single aisle aircraft. The high lift system consists among other components of an outer landing flap, which is carried by two supports. The complete high-lift system is attached to the wing trailing edge as well as to the wing underside. In order to increase productivity in aircraft assembly, the high-lift system will be delivered pre-assembled to the final assembly line where it will be mounted to the wing following a plug and fly concept. Figure 1 shows a simplified model of the high lift system. It is derived on a scale of 1:2 from the real $[1,2]$ system and represents the outboard flap of a left wing. 


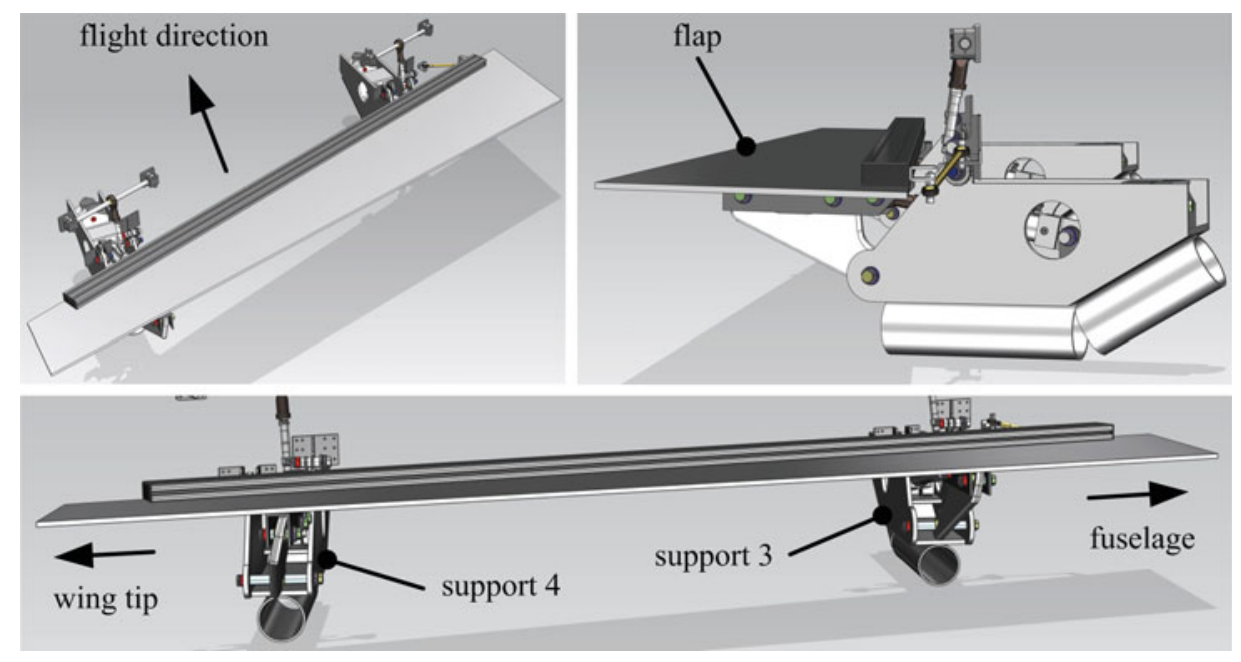

Fig. 1 Isometric, side and rear view of derivative product (simplified model of real product)

\section{Jigs and Fixtures for Assembling Aircraft Components}

Jigs and fixtures are used wherever components must be precisely aligned with each other. In the production of aircraft components, the greatest assembly effort is required when joining sheet metal parts and components made of carbon fiber reinforced plastics (CFRP). Therefore, most fixtures are used for this purpose. Conventionally, jigs and fixtures are inflexible and have no adaptability in case of product changes. Millar and Kihlman derive the need for reconfigurable fixtures from the example of wing box assembly [3]. Due to the size and the manufacturing effort, the introduction of a new jig can take more than 24 months, which contradicts a short time to market. They present a concept for a reconfigurable jig for the assembly of wing boxes. Therefore they propose the use of off-the-shelf components and the introduction of design tools [3]. Jigs can also consist of plug-in systems that ensure reconfigurability of the system. Zhang et al. present a modular system that allows a high reusability in case of product changes [4]. It consists of a reconfigurable frame system, relocatable clamps and additional parts. The flexible positioning of the clamps reduces the design effort and shortens the implementation time. An adaptation to the assembly situation is not considered. An ergonomic working method is therefore not promoted.

In many research projects, industrial robots are integrated into the jigs in order to create an adaptivity to the assembly situation. The goals are a faster adaptation to product changes, the compensation of shape and position errors and the full automation of joining 
processes $[5,6,7]$. Improving ergonomics is therefore not the focus of these approaches. Schwake and Wulfsberg have developed a handling system for manipulating shell parts for aircraft bodies [5]. Instead of a rigid jig, an industrial robot takes over the positioning of the components. Linear actuators integrated into the end effector can additionally correct shape deviations by pressing on the shell part. It is emphasized that the application requires collaborative robots, since humans are located in the work area [5]. Schmitt et al. pursue the goal to develop an automated metrology assisted robot based positioning and untwist process. The process shall replace rigid jigs by a programmable robot system [6]. They are developing a model of the components deformation behavior to determine the necessary compensatory movements of the robots. A similar approach is presented in Ramirez and Wollnack [7]. Here a flexible assembly system for CFRP structures is investigated. For a fully automated joining process, a six-axis robot carrying the tool is combined with a flexible jig. The jig includes hexapod robots to correct shape and position deviations. A 3D surface measurement system supports the detection of deviations and enables the robots to make corrections.

In other approaches, an attempt is made to work without a special jig. Mozillo et al. present an assembly process without a jig [8]. The authors describe that jigs and tools are monolithic and have to be designed rigidly due to the high tolerance requirements. The use of laser trackers to determine the exact position and alignment of the components makes rigid jigs unnecessary. This approach also improves the ergonomics of the work process [8]. All presented work and approaches focus on the assembly of structural components for wing box or fuselage. Adaptable jigs supporting the ergonomic assembly of systems with moveable parts were not found.

\section{Development of Adaptive Assembly Jig}

In the development of the adaptive device the concept was designed according to the construction guideline VDI 2221 [9]. The challenges in the assembly process of landing flaps, as will be described in the section below, such as the ergonomic risks of overhead work, were taken into account. Therefore, four general aims are essential for the definition of detailed requirements. The first goal is to promote an ergonomic and intuitive working method. Second, the device should ensure accessibility to the assembly spots and third, the device must support the simultaneous assembly activity of several assembly workers at the same product. Last but not least the assembly jig must support the plug \& fly concept of the high lift system. In a detailed analysis of the requirements, the following major criteria were identified. 


\subsection{Requirements Analysis}

In terms of the basic function of the assembly jig, it must be capable of receiving and holding the assembly and all components required for it at all stages of the assembly process. Loose parts must be fixed at least until they are fully attached to the assembly. In order to ensure a high utilization of the assembly jigs, the jigs must be able to accommodate both left and right wing high lift systems as well as inboard and outboard systems. The worker should be able to freely adjust the working height to support an ergonomic working procedure. There should also be a possibility to rotate the product so that it can be brought into different orientations depending on the assembly spot. The assembly workshops previously conducted with the derivative product have shown that employees would like to swivel and rotate the product around two axes in order to reach all assembly spots $[10,11]$. The motion axes and the motion range must be dimensioned in such a way that no overhead work and no work in kneeling or bending occurs. Ideally, the degrees of freedom of the jig are selected so that the assembly can be brought into a position and orientation that allows workers of different heights to work on the assembly simultaneously and ergonomically. The jig must be designed in such a way that its elements do not impede or obscure the accessibility of the assembly spots at any time.

There can be significant dimensional variations during manufacturing and assembly of the wing box [12]. To support the plug \& fly concept the actual dimensions of the attachment points generated and measured during the production of the wing box must be exactly reproduced by the assembly jig. Therefore, appropriate adjustment possibilities must be provided inside the jig. The completely assembled high-lift system should also be adjusted in the assembly jig and a function test should be carried out, so that the adjustment and calibration work in the final assembly line can be reduced to a minimum. In order to support the entire assembly, the jig must have a total load-bearing capacity of at least $600 \mathrm{~kg}$. Even during the functional test, where the center of gravity is shifted by the extended flap, the load capacity and stability of the jig must be ensured. To protect the employees, all moving components must be secured against the danger of squeezing. An automatic force and power limitation during contact between man and machine would be desirable.

It is expected that the sample product will be manufactured in a cycle line to increase productivity. Since the assembly cannot be transferred from one assembly jig to the next due to its instability, the assembly jig itself must be mobile to transport the product from station to station. Since only the supports are assembled during the first assembly steps, and thus the dimensions of the assembly are still very limited in relation to the finished product, a modular design of the jig is desirable. It allows the jig to adapt its size and functions according to the progress of the production process. 


\subsection{Basic Concept for an Adaptive Jig}

As described in the requirements, the assembly jig must adapt the pose of the assembly to both the physical conditions of the workers and the respective assembly step. For this purpose, several systems were drafted with creativity techniques and assessed afterwards. For lack of space, only the final concept, called assembly wheel, is presented in this article.

The principle sketch in Fig. 2 represents the components of the basic concept by oversimplified elements in order to essentialize the idea of the assembly wheel. The significant components of the system, like the robot arms and the ring shaped structure are greatly simplified to facilitate the understanding of the system. The concept suggests the collaboration of two or more robot arms. The robot arms lift and hold the components and position them both in relation to each other and in the desired pose relative to the worker. The special feature of the assembly wheel is the arrangement of the robot arms on a ring shaped seventh axis. This creates motion redundancy for the robots. They can thus change their arrangement without moving the product and create situation-specific work space for the worker. This is necessary to ensure accessibility to all assembly spots. The two or more robot arms must hold the assembly together. The task allocation could be such that one robot arm carries the main load of the assembly and the other arms hold and position the components to be assembled. The worker then carries out the actual joining. This would not only reduce the physical strain on the worker, but also relieve him of cognitive work as pre-programmed robotic motions guide him through assembly operations. Another major advantage is the free positioning and orientation of the workpiece corresponding to the demands of the workers. The improved accessibility through individual height adjustment promotes ergonomic assembly work, even when several technicians work together on the assembly object. Furthermore, the jig can easily be adapted to
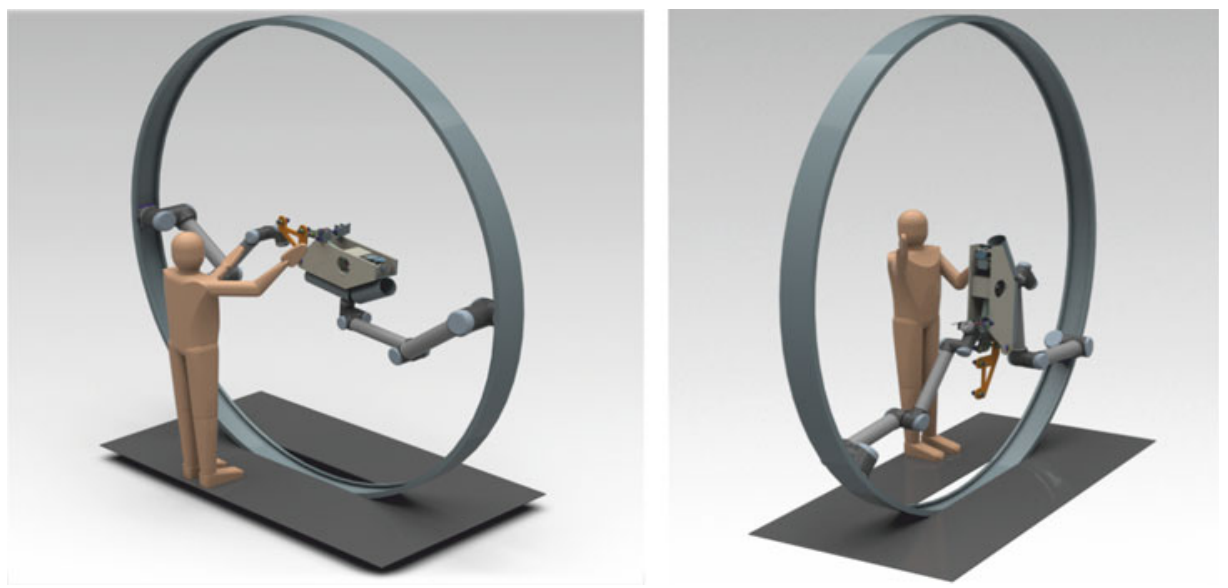

Fig. 2 Principal sketch of assembly wheel concept (not to scale) 
changes in the production process or to new variants of the assembly product. Since all assembly steps can be executed with the same jig, there is no need to transfer the product between different specialized jigs during the assembly process. The presented concept leads to a very complex system which is more expensive than a conventional jig. But the posted advantages of the assembly wheel surpass this drawback. A patent has been applied for the principle of the assembly wheel.

\subsection{Draft Design of Assembly Wheel}

From the basic concept shown in Fig. 2, a draft design with real dimensions was developed, taking the example product into account. Figure 3 shows a 3D model of the draft. The assembly wheel is made of a circular bent steel beam. Profiled rail guides at both sides of the wheel provide precise guidance for the carriages on which the robots are installed. Even with a very stiff design of the wheel there will be some deformation of the wheel while the robots travel along the circumference. This will have negative influence on the position accuracy of the robots. The implementation of an indoor GPS can help to decrease the relative positioning error between the cooperating robots [13]. Norman et al. show that the achievable accuracy can be at least within $0.3 \mathrm{~mm}$ [13]. How a workpiece can be handled by two cooperating industrial robots is discussed in Spiller and Verl [14] for example. Since conventional collaborative robots do not provide sufficient payload, the usage of standard industrial robots with high payload is proposed. To avoid injuries to the worker, the robots need to be enabled for human-robot-collaboration. In Behrens [15] different safeguarding techniques are presented. The authors successfully developed and tested devices for hand-guiding, power and force limiting as well as for speed and separation monitoring [15]. For the assembly wheel a combined system is most suitable. A hand-guiding function gives the workers the ability to manually set the position of the components while a power and force limiting function protects the workers during autonomous movements of the robots.
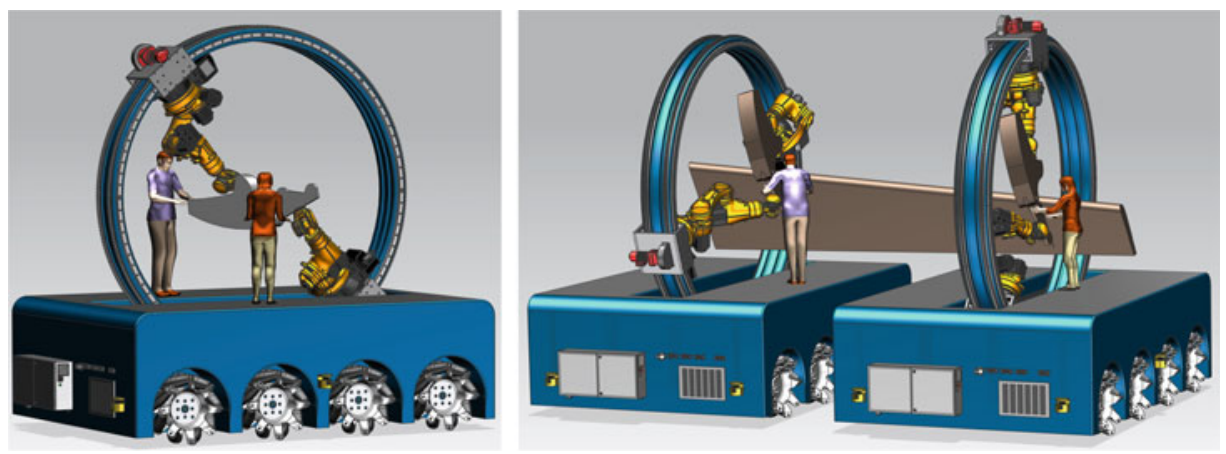

Fig. 3 Advanced 3D model of assembly wheel concept in real scale 
The platform is designed as an automated guided vehicle. The Mecanum wheels allow omnidirectional driving maneuvers and thus facilitate the positioning in a workstation. High performance batteries inside the platform provide the necessary power for the traction motors and the robot systems. Charging can be done in the assembly stations while the platform stands still.

To study the feasibility of the assembly process with an adaptive jig, human modelling in Siemens NX has been used. Therefore the assembly process has been divided into thirteen assembly steps. For each assembly step, the robots of the assembly wheel are positioned so that they do not obstruct accessibility for the respective assembly spots. Human models for the 95th and 5th percentiles of both the male and female population were loaded and placed at the jig. The position and orientation of the assembly was then adapted to the human models so that their working posture is largely ergonomic. To estimate the degree of physical stress of the workers, the key indicator method (developed by Federal Institute for Occupational Safety and Health [16]) was used. It has been observed that the adaptive jig sufficiently supports ergonomic working for every human model in every assembly step. None of the working steps causes increased or even high physical stress. However, the study with CAD models cannot answer any questions regarding the workers' personal feeling of safety. It is assumed that the collaboration with the powerful robots and the high rising assembly wheel can lead to fears among the employees.

\section{Derivation of a Physical Demonstrator}

For the practical evaluation of the idea of adaptive jigs for the assembly of large-scale components a physical demonstrator is required. In the first step, the basic influences of an adaptive jig on the assembly process, the support of an ergonomic working method and the personal feelings of the workers when working with an adaptive jig are to be investigated. A simplified jig without industrial robots is sufficient for the experiments required for this purpose. Only in the second step, the construction of a complex experimental fixture according to Fig. 3 with a circular track and industrial robots is reasonable to demonstrate the technical feasibility of the assembly wheel concept and to investigate the achievable position accuracy as well as methods for path planning.

A demonstrator with a simplified kinematic concept was designed and built. The demonstrator was designed on a scale of 1:2 to match the derivative product from Fig. 1 . As can be seen in Fig. 4 (left), the assembly jig consists of three platforms. The outer platforms are supported on air cushions and can thus be easily moved in all directions. On these platforms the supports are pre-assembled. The center platform is stationary and hosts the landing-flap pre-assembling. The right side of the picture shows how the outer platforms with the pre-assembled supports are docked to the center platform for finalizing the assembly of the derivative product. 

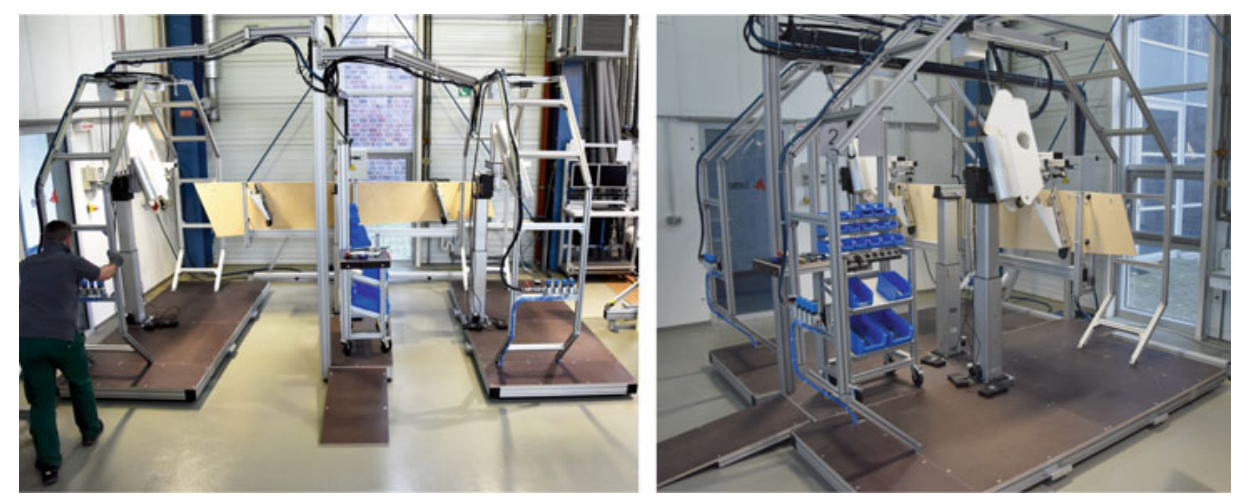

Fig. 4 The jig demonstrator with two mobile jigs and one stationary platform

All platforms have a lifting column for adjusting the working height. The lifting columns can be moved individually or synchronously by means of a hand switch or pedal. In the mobile platforms a rotary module is placed on the lifting columns. This allows the support to be rotated about the transverse axis during pre-assembly. As a reference to the assembly wheel concept an octagonal frame made of aluminum profile is added to the mobile platforms. This structure gives the workers the feeling of working inside the wheel and provides interfering contours similar to the circular track. Integrated lamps provide adequate lighting for the assembly areas.

In Fig. 5 the pre-assembly of a support and the landing flap is shown. The mobile jig docks to another stationary platform for pre-assembly. On this platform, the material and tools are provided in small rack trolleys. The pre-assembly platform also increases the movement area for the worker. The basic bodies of the supports are provided on small carriages. The worker attaches the holder to the support and then lifts it out of the cart with
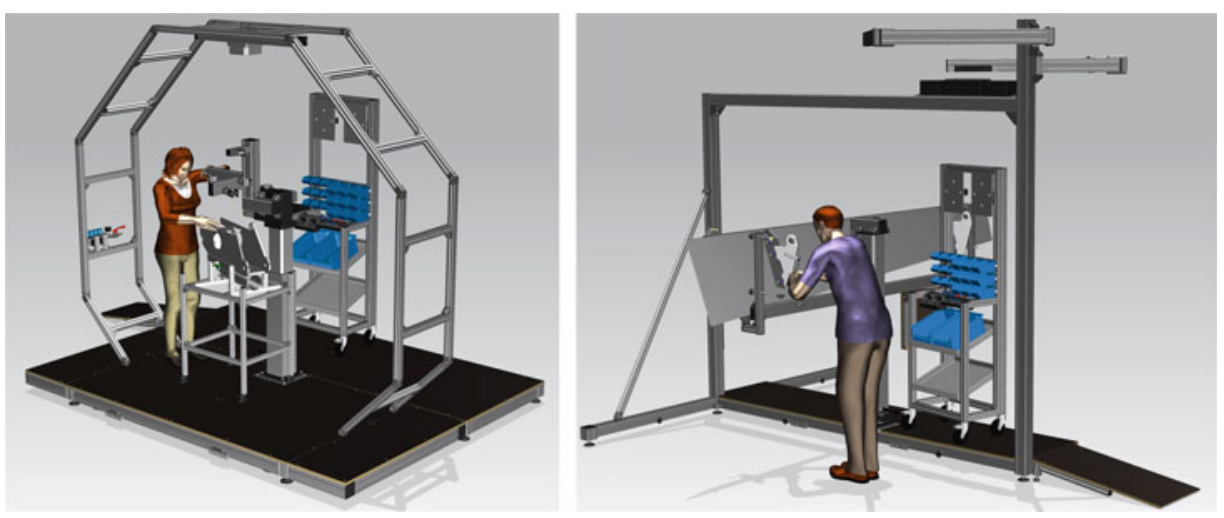

Fig. 5 Mobile jig stopped at preassembly platform (left). Preassembly of landing flap at the base platform (right) 

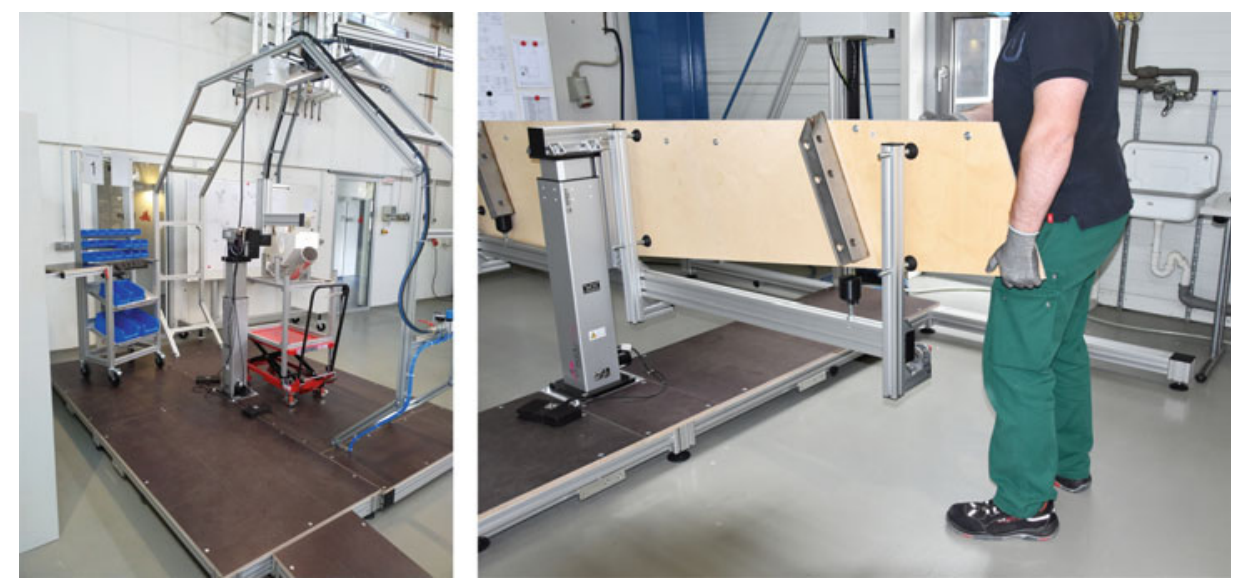

Fig. 6 Preparation for mounting support \#3 to jig on mobile platform (left). Mounting of landing flap to the jig on the center platform (right)

the lifting column. The photos in Fig. 6 show the demonstrator prepared for an assembly test with the derivative product. The design of the demonstrator allows to use it with and without the adaptive functions. This way the performance of an adaptive jig can be benchmarked against a conventional jig.

\section{Conclusion and Outlook}

The presented results show that assembly jigs for future high-lift systems mandate special requirements that are not fulfilled by traditional jig designs. To support the assembly of plug and fly components, jigs are required that can position components dynamically in relation to each other, that are mobile and can adjust the orientation of the component to be assembled according to the assembly situation. The assembly wheel was developed as a concept to meet these requirements. The components are carried by several industrial robots, which allow a free positioning in space. To increase the freedom of movement, the robots are mounted on a circular path. This allows them to move in different positions to clear the workspace for the worker. In a study with a 3D model it was shown that the concept of the assembly wheel allows an ergonomic assembly of the components and that especially people of different heights can work comfortably on the product. The automatic generation of the robot target positions and the determination of the required path movements have not been considered so far and represent a great challenge. Therefore, further research projects have to be carried out in order to enable the full potential of the assembly wheel concept. For the practical evaluation of adaptive jigs, a simplified demonstrator on a scale of 1:2 was built. It will be used in a practical test series to examine in particular the process capability and the physical and psychological effects of adaptive jigs. 
Acknowledgements The results presented in this paper were developed in the research project "Next.Move - Next Generation of Moveables" funded under the program Luftfahrtforschungsprogramm LuFoV-2, FKZ 20W1512G by Federal Ministry for Economic Affairs and Energy (BMWi).

Open Access This chapter is licensed under the terms of the Creative Commons Attribution 4.0 International License (http://creativecommons.org/licenses/by/4.0/), which permits use, sharing, adaptation, distribution and reproduction in any medium or format, as long as you give appropriate credit to the original author(s) and the source, provide a link to the Creative Commons license and indicate if changes were made.

The images or other third party material in this chapter are included in the chapter's Creative Commons license, unless indicated otherwise in a credit line to the material. If material is not included in the chapter's Creative Commons license and your intended use is not permitted by statutory regulation or exceeds the permitted use, you will need to obtain permission directly from the copyright holder.

\section{References}

1. Bader, A., Gebert, K., Hogreve, S., Tracht, K.: Derivative products supporting product development and design for assembly. Procedia Manuf. 19, 143-147 (2018)

2. Gebert, K., Bader, A., Tracht, K.: Decision tool for designing derivative products for supporting assembly planning of large-volume assembly groups. Procedia CIRP 76, 31-35 (2018)

3. Millar, A., Kihlman, H.: Reconfigurable flexible tooling for aerospace wing assembly. SAE Technical Paper 2009-01-3243 (2009)

4. Zhang, H., Zheng, L., Chen, X., Huang, H.: A novel reconfigurable assembly jig based on stable agile joints and adaptive positioning-clamping bolts. Procedia CIRP 44, 316-321 (2016)

5. Schwake, K., Wulfsberg, J.: Robot-based system for handling aircraft shell parts. Procedia CIRP 23, 104-109 (2014)

6. Schmitt, R., Witte, A., Janßen, M., Bertelsmeier, F.: Metrology assisted assembly of airplane structure elements. Procedia CIRP 23, 116-121 (2014)

7. Ramirez, J., Wollnack, J.: Flexible automated assembly systems for large CFRP-structures. Procedia Technology 15, 447-455 (2014)

8. Mozillo, R. Iaccarino, P., Vitolo, F., Franciosa, P.: Design and development of jigless assembly process: the case of complex aeronautical systems. In: 2019 II Workshop on Metrology for Industry 4.0 and IoT, pp. 132-136. IEEE (2019)

9. Jänsch, J., Birkhofer, H.: The development of the guideline VDI 2221 - the change of the direction. In: Marjanović, D. (ed.) Proceedings of the DESIGN 2006 / 9th International Design Conference, vol. 1, pp. 45-52. Faculty of Mechanical Engineering and Naval Architecture, University of Zagreb; The Design Society, Glasgow (2006)

10. Gebert, K., Onken, A.-K., Tracht, K.: Assembly workshops for acquiring and integrating expert knowledge into assembly process planning using rapid prototyping model. In: Schüppstuhl, T., Tracht, K., Franke, J. (eds.) Tagungsband des 3. Kongresses Montage Handhabung Industrieroboter, pp. 13-21. Springer Vieweg, Berlin, Heidelberg (2018) 
11. Krist, K., Sievers, T., Onken, A.-K., Kodjo, Y., Tracht, K.: Application of derivative products for integration expert knowledge into assembly process planning. Procedia CIRP 88, 88-93 (2020)

12. Saadat, M., Cretin, C.: Dimensional variations during Airbus wing assembly. Assem. Autom. 22(3), 270-276 (2002)

13. Norman, A.R., Schönberg, A., Gorlach, I.A., Schmitt, R.: Validation of iGPS as an external measurement system for cooperative robot positioning. Int. J. Adv. Manuf. Technol. 64, 427446 (2013)

14. Spiller, A., Verl, A.: Force controlled handling with cooperating industrial robots. In: ROBOTIK 2012 - 7th German Conference on Robotics, pp. 496-501. VDE Verlag, Berlin (2012)

15. Behrens, R., Saenz, J., Vogel, C., Elkmann, N.: Upcoming technologies and fundamentals for safeguarding all forms of human-robot collaboration. In: Proceedings of 8th International Conference Safety of Industrial Automated Systems - SIAS 2015, pp 18-23. Deutsche Gesetzliche Unfallversicherung (DGUV), Berlin (2015)

16. Gefährdungsbeurteilung bei physischer Belastung - die neuen Leitmerkmalmethoden (LMM) Kurzfassung. 3rd edn. Bundesanstalt für Arbeitsschutz und Arbeitsmedizin (BAuA), Dortmund, Berlin, Dresden (2019) (in German)

Open Access This chapter is licensed under the terms of the Creative Commons Attribution 4.0 International License (http://creativecommons.org/licenses/by/4.0/), which permits use, sharing, adaptation, distribution and reproduction in any medium or format, as long as you give appropriate credit to the original author(s) and the source, provide a link to the Creative Commons license and indicate if changes were made.

The images or other third party material in this chapter are included in the chapter's Creative Commons license, unless indicated otherwise in a credit line to the material. If material is not included in the chapter's Creative Commons license and your intended use is not permitted by statutory regulation or exceeds the permitted use, you will need to obtain permission directly from the copyright holder.

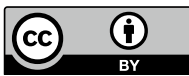

